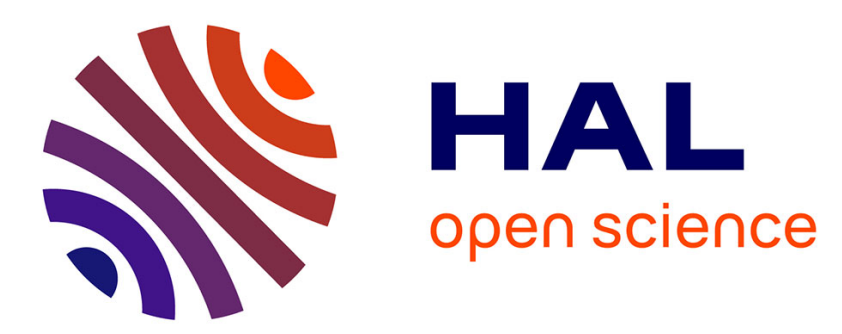

\title{
Adhesion and leakage current characteristics of selective CVD tungsten films on the silicon substrate
}

\author{
C. Lee, Y. Im, J. R. Lee
}

\section{To cite this version:}

C. Lee, Y. Im, J. R. Lee. Adhesion and leakage current characteristics of selective CVD tungsten films on the silicon substrate. Journal de Physique IV Proceedings, 1993, 03 (C3), pp.C3-433-C3-440. 10.1051/jp4:1993360 . jpa-00251417

\section{HAL Id: jpa-00251417 https://hal.science/jpa-00251417}

Submitted on 1 Jan 1993

HAL is a multi-disciplinary open access archive for the deposit and dissemination of scientific research documents, whether they are published or not. The documents may come from teaching and research institutions in France or abroad, or from public or private research centers.
L'archive ouverte pluridisciplinaire HAL, est destinée au dépôt et à la diffusion de documents scientifiques de niveau recherche, publiés ou non, émanant des établissements d'enseignement et de recherche français ou étrangers, des laboratoires publics ou privés. 


\title{
Adhesion and leakage current characteristics of selective CVD tungsten films on the silicon substrate
}

\author{
C. LEE, Y.J. IM* and J.G. LEE* \\ Department of Metallurgical Engineering, Inha University, 253 Yonghyun-dong, Inchon 402-751, Korea \\ "Samsung Electronics, P.O. Box 37, Suwon, Korea
}

\begin{abstract}
In this study we investigated the effects of $\mathrm{SF}_{6}$ and $\mathrm{CF}_{4}$ plasma pretreatments on the adhesion and junction leakage characteristics of the selective CVD $\mathrm{W}$ films by $\mathrm{SiH}_{4}$ reduction of $\mathrm{WF}_{6}$ on the $\mathrm{Si}$ substrate. The $\mathrm{SF}_{6}$ plasma pretreatment performed in situ prior to $\mathrm{W}$ deposition to remove the polymer films in contact holes results in enhancement of the adhesion of $\mathrm{W}$ films to the $\mathrm{Si}$ substrate but degradation of junction leakages due to vertical and lateral $\mathrm{Si}$ consumptions. The $\mathrm{CF}_{4}$ plasma pretreatment performed as the last step of the reactive ion etching for contact window opening produced the W/Si contacts of good adhesion, low contact resistances and low junction leakages for thin $W$ films, while it produced the W/Si contacts of poor adhesion and high contact resistances for thick $W$ films. The selective CVD $W$ films deposited by the three step process of $\mathrm{SiH}_{4}$ reduction/in situ annealing/ $\mathrm{SiH}_{4}$ reduction was found to have both good adhesion and low junction leakage characteristics.
\end{abstract}

\section{1) INTRODUCTION}

Selective CVD W is an attractive technology for filling contact holes and via holes with high aspect ratio in very large scale integrated circuits. The reduction of tungsten hexafluoride $\left.\left(W_{6}\right)_{6}\right)$ by silane $\left(\mathrm{SiH}_{4}\right)[1-3]$ is generally preferred to the reduction of $\mathrm{WF}_{6}$ by hydrogen[4] in the selective $W$ process, since the former provides higher deposition rate and produces $W$ fihns without the problems of encroachment and tunneling[5, 6] which lead to junction leakages. However, the silane reduced W films also have several drawbacks such as less good step coverage and imperfect adhesion. Lifting or peeling of $W$ films which sometimes occurs in contact holes is one of the major obstacles in developing the silane reduced selective CVD W technology. Besides them the silane reduced $W$ films have the problem of junction leakages which are not low enough to accept for mass production, although the leakages are much lower than those of the hydrogen reduced $W$ films.

The $\mathrm{SF}_{6}$ or $\mathrm{CF}_{4}$ plasma pretreatment[7,8] is commonly performed prior to the selective $\mathrm{W}$ film deposition to remove the surface area of the $\mathrm{Si}$ substrate damaged by the ion implantation for $\mathrm{n}^{+}$diffusions[9] and the polymer film produced during the dry etching for contact hole opening which result in high contact resistances. However, the excessive $\mathrm{Si}$ etching due to the high etch rate of $\mathrm{SF}_{6}$ etching is likely to $c$ ause vertical and lateral $\mathrm{Si}$ consumptions which lead to junction leakages. The purpose of this paper is to investigate the effects of the $\mathrm{SF}_{6}$ and $\mathrm{CF}_{4}$ plasma pretreatments on the adhesion and junction leakage characteristics of the silane reduced selective CVD W films. 


\section{2) EXPERIMENTAL}

The active regions were defined on p-type (100) $\mathrm{Si}$ wafers by standard local oxidation of $\mathrm{Si}$ (LOCOS) process. The $\mathrm{n}^{+} / \mathrm{p}$ junctions were formed by As ion implantation with an energy of $40 \mathrm{KeV}$ at a dosage of $5 \times 10^{15}$ atoms $/ \mathrm{cm}^{2}$ followed by annealing at $900 \mathrm{C}$ for $60 \mathrm{~min}$. The junction depths for the $\mathrm{n}^{+}$diffusions were about $0.25 \mathrm{~km}$. After the deposition of the $900 \mathrm{~nm}$ borophosphosilicate glass (BPSG) layer contact holes were patterned and etched using the reactive ion etching (RIE) technique. Wafers were then precleaned by immersion in $\mathrm{H}_{2} \mathrm{SO}_{4}$ $\mathrm{H}_{2} \mathrm{O}_{2}$ and 100:1 $\mathrm{HF}$ solutions followed by a $10 \mathrm{~min}$ rinse in $\mathrm{H}_{2} \mathrm{O}$ and spin drying. Prior to the W film deposition the $\mathrm{Si}$ surface was etched by the $\mathrm{CF}_{4}$ plasma etching as the last step of the RIE for contact hole opening or the $\mathrm{SF}_{6}$ plasma etching in the $\mathrm{W}$ deposition chamber to remove the polymer residues at the bottom of contact holes. This in situ plasma pretreatment is often called a $\mathrm{Si}$ polishing procedure in the industry.

W films were subsequently deposited selectively in the contact holes on the $\mathrm{n}^{+} / \mathrm{p}$ diodes using silane reduction in a commercial single wafer cold wall LPCVD reactor. The reaction chamber was pumped with a turbomolecular pump and the working base pressure of the mid $10^{-7}$ torr was maintained during the deposition. Wafers were heated from the front side of the wafers using the IR lamp. The process parameters were : substrate temperature $=300 \mathrm{C}$, pressure $=100 \mathrm{mtom}, \mathrm{SiH}_{4}$ flow $=10 \mathrm{cc} / \mathrm{min}, \mathrm{WF}_{6}$ flow $=20 \mathrm{cc} / \mathrm{min}, \mathrm{H}_{2}$ flow $=1,000 \mathrm{cc} / \mathrm{min}$. After the W deposition the Al-1\%Si film $600 \mathrm{~nm}$ thick was sputter-deposited followed by annealing at $450 \mathrm{C}$ for $30 \mathrm{~min}$ in the mixture of $\mathrm{H}_{2}$ and $\mathrm{N}_{2}$.

W/Si contact resistances were measured using the test stucture shown in Fig. 1(a). The test pattem consists of 360 contact holes. Junction leakages of the $\mathrm{n}^{+} / \mathrm{p}$ diodes were measured at $5 \mathrm{~V}$ reverse bias using the test struture shown in Fig. 1(b). To evaluate the effects of the lateral distance from a contact window edge to an adjacent field oxide edge $(\Delta \mathrm{L})$ on the adhesion and junction leakages of the selective CVD W films, test patterns with various $\Delta$ L's $(0.1,0.19,0.28$ and $0.36 \mu \mathrm{m})$ were used.
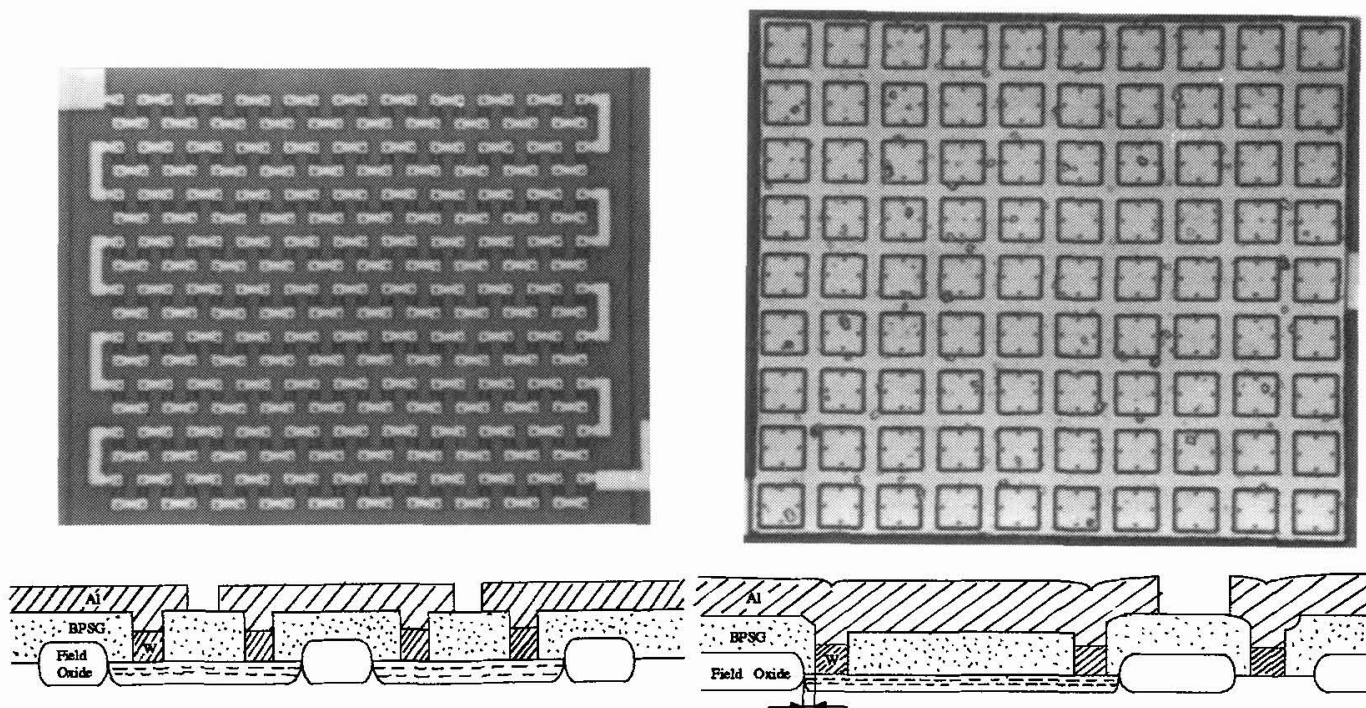

(a)

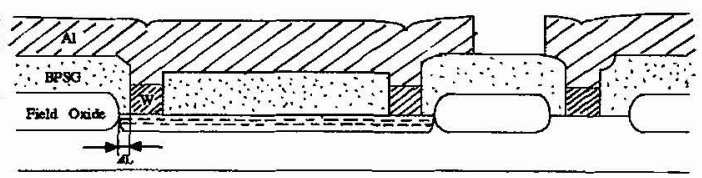

(b)

Fig. 1. The test structure used to measure $\mathrm{W} / \mathrm{n}^{+}$contact resistances : (a) surface SEM micrograph and schematic corss-sectional view and (b) The test structure used to measure $\mathrm{W} / \mathrm{n}^{+} / \mathrm{p}$ junction leakage currents : surface SEM micrograph and schematic corss-sectional view 


\section{3) RESULTS AND DISCUSSION}

Figs. 2(a) and 2(b) show the cross-sectional SEM micrograph of a contact hole and the surface SEM micrograph of a scribe line filled with $W$ deposited using silane reduction at $300 \mathrm{C}$ for $120 \mathrm{sec}$. Prior to $\mathrm{W}$ deposition wafers were precleaned using a dilute HF dip to remove native oxides but were not given the plasma pretreatment. We can see that W films are lifted partially from the $\mathrm{Si}$ substrate in the contact hole (Fig.2(a)) and peeled off in the scribe line (Fig. 2(b)). The dark area at the bottom of the contact hole (Fig. 2(a)) is the void formed by $W$ lifting and the bright area on the right side of the scribe line (Fig. 2(b)) is the place where $W$ films are peeled off and gone. There was no lifting of as-deposited W films from the $\mathrm{Si}$ substrate either in the contact hole or in the scribe line. However, the $\mathrm{W}$ films in some contact holes and scribe lines were peeled off during the annealing process at $450 \mathrm{C}$ for $30 \mathrm{~min}$ in the mixture of $\mathrm{H}_{2}$ and $\mathrm{N}_{2}$ after Al deposition. The contact resistances at the contact holes where $\mathrm{W}$ films were lifted or peeled off were very high (> $1 \mathrm{~K} \Omega$ ).

To remove the polymer film produced during the reactive ion etching for contact hole opening the $\mathrm{SF}_{6}$ plasma pretreatment was performed in situ in the $\mathrm{W}$ deposition chamber prior to $\mathrm{W}$ deposition. The optimized $\mathrm{SF}_{6}$ plasma etching conditions were : if power $=20$ watt, total pressure $=50 \mathrm{mtorr}, \mathrm{SF}_{6}$ flow $=30 \mathrm{cc} / \mathrm{min}$, time $=15 \mathrm{sec}$. W films $500 \mathrm{~nm}$ thick were then deposited at $300^{\circ} \mathrm{C}$. The contact resistances and the junction leakage currents for the selective CVD W film deposited by $\mathrm{SiH}_{4}$ reduction on the $\mathrm{n}^{+} / \mathrm{p}$ diodes with the in situ $\mathrm{SF}_{6}$ plasma pretreatment are shown in Figs. 3(a) and 3(b), respectively. The contact resistances were measured for the $\mathrm{W} / \mathrm{n}^{+}$contacts while the leakage currents were for the $\mathrm{n} / \mathrm{p}$ junctions. The W films in the contact holes were not lifted, although the contact resistances (Fig. 3(a)) are about $100 \mathrm{ohm}$ higher than those for the $\mathrm{Al} / \mathrm{n}^{+}$contacts with no $\mathrm{W}$ used as standards (Fig. 4(a)). However, the junction leakages for the $\mathrm{W} / \mathrm{n}^{+}$contacts with the $\mathrm{SF}_{6}$ plasma pretreatment (Fig. 3(b)) are considerably higher than those for the $\mathrm{Al} / \mathrm{n}^{+}$contacts (Fig. 4(b)) and thus too



(a)



(b)

Fig. 2. SEM micrographs showing lifting of the selective CVD $W$ films (a) in a contact hole (cross-sectional view) and (b) at a scribe line (plan view) 


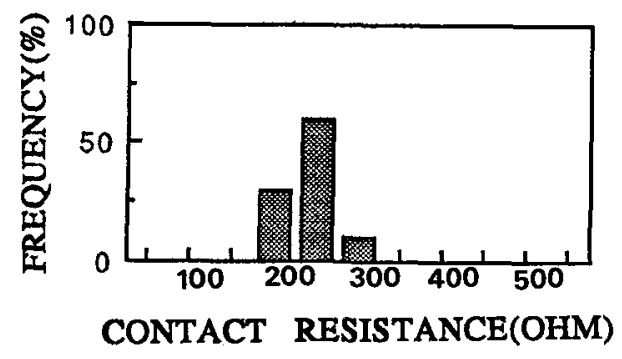

(a)

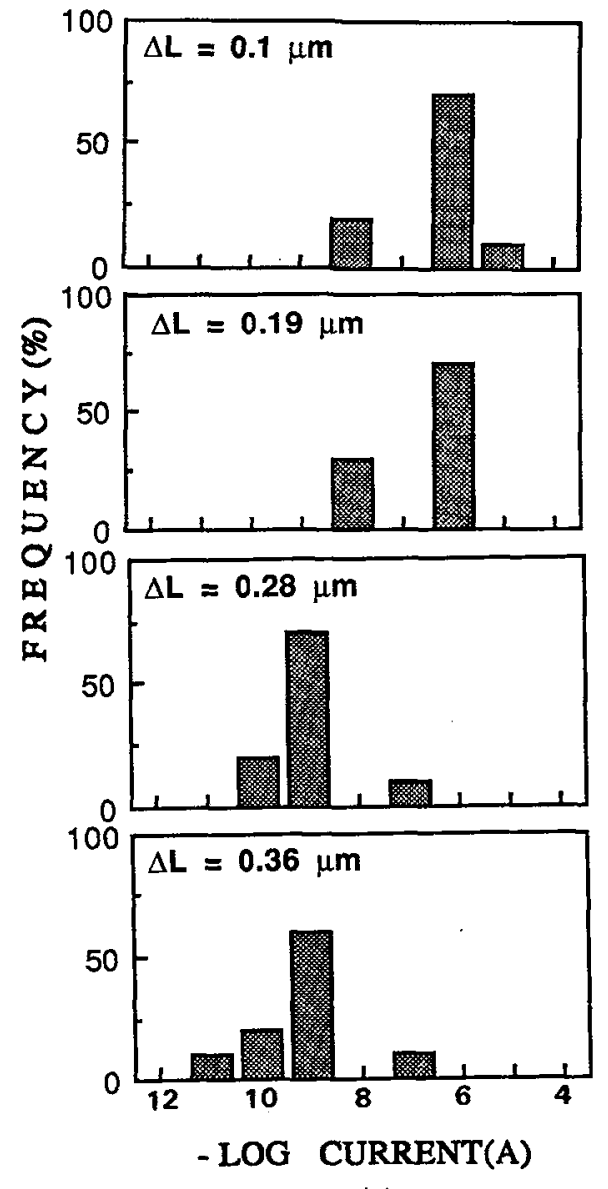

(a)

Fig. 3. Histograms showing (a) the contact resistance distribution and (b) the junction leakage distribution at $5 \mathrm{~V}$ reverse bias for the $\mathrm{SiH}_{4}$ reduced selective CVD W films with $\mathrm{SF}_{6}$ plasma pretreatment.

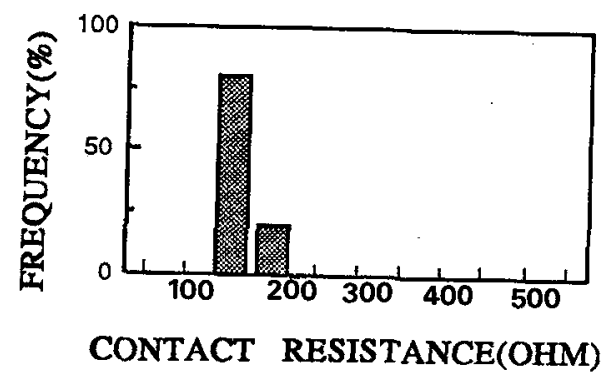

(b)

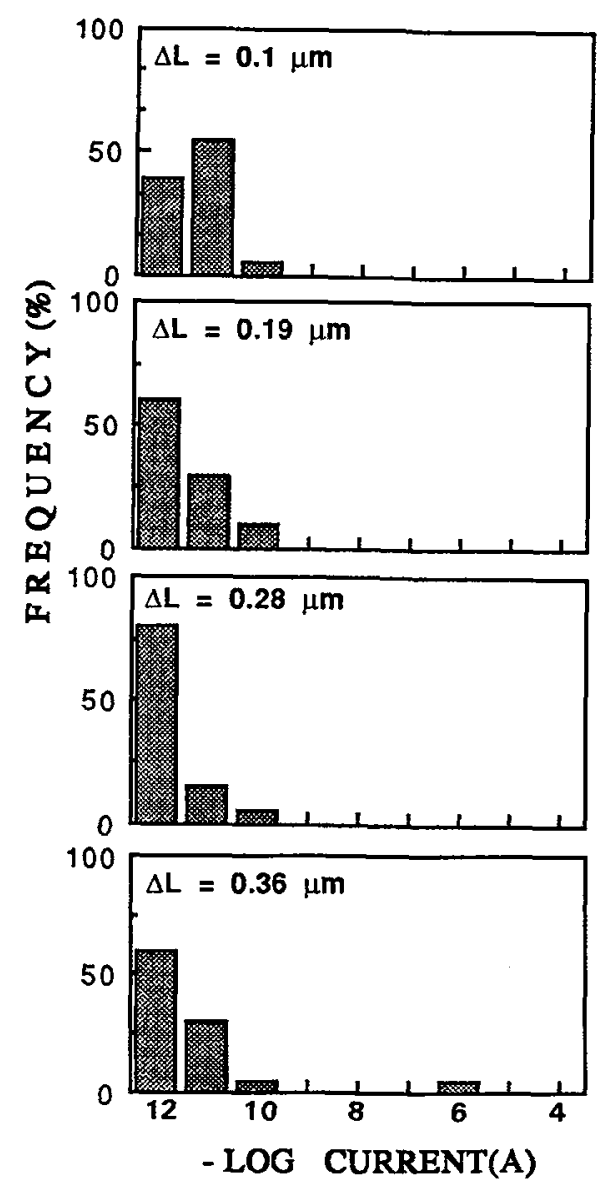

(b)

Fig. 4. Histograms showing (a) the contact resistance distribution and (b) the junction leakage distribution at $5 \mathrm{~V}$ reverse bias for the $\mathrm{Al} / \mathrm{n}^{+}$contacts used as standards 


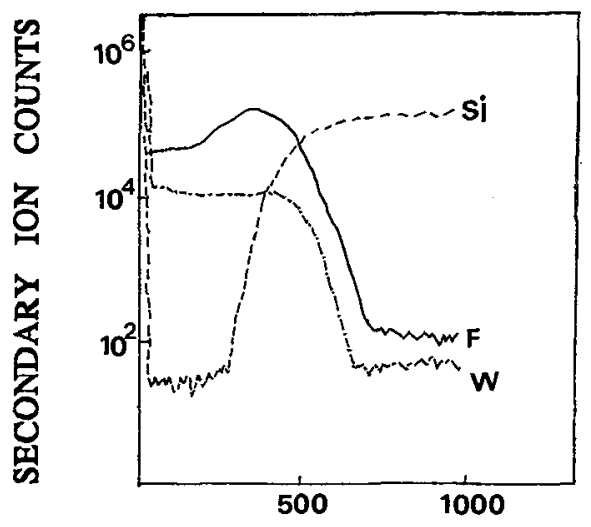

SPUTTERING TMME(SEC)



SPUTTERING TIME(SEC)

(a)

(b)

Fig. 5. SIMS depth profiles of the selective CVD W film on the Si substrate (a) with and (b) without $\mathrm{SF}_{6}$ plasma pretreatment

high to accept. Also junction leakages tend to increase with decreasing $\Delta \mathrm{L}$. This implies that junction leakages are mainly caused by the lateral $\mathrm{Si}$ consumptions under the $\mathrm{Si}-\mathrm{SiO}{ }_{2}$ interface as well as the vertical $\mathrm{Si}$ consumptions. The high etch rate of the $\mathrm{SF}_{6}$ plasma etching readily consumes up the $\mathrm{Si}$ in shallow junctions and in turn causes junction leakages and high contact resistances. We made every effort to lower the $\mathrm{SF}_{6}$ plasma etch rate further by changing the etching process parameters but failed to because of the hardware limitations of the $W$ deposition system. The lateral $\mathrm{Si}$ consumptions seem to be caused by the incorporation of the $F$ species from $\mathrm{SF}_{6}$ plasma into the $\mathrm{Si}$ substrate along the $\mathrm{Si}-\mathrm{SiO}{ }_{2}$ interface. We can see $\mathrm{F}$ piled up at the $\mathrm{W}-\mathrm{Si}$ interface after the $\mathrm{SF}_{6}$ plasma etching from the comparison of the SIMS depth profiles of the selective CVD W films with (Fig. 5(a)) and without (Fig. 5(b)) the $\mathrm{SF}_{6}$ plasma pretreatment.

$\mathrm{Si}$ etching with $\mathrm{CF}_{4}$ plasma is also commonly performed instead of the in situ $\mathrm{SF}_{6}$ plasma pretreatment to remove the polymer films in contact holes prior to the $W$ deposition. The $\mathrm{CF}_{4}$ plasma etching is known to have the advantages of a bower $\mathrm{Si}$ etch rate and a higher degree of anisotropy over the $\mathrm{SF}_{6}$ plasma etching. The $\mathrm{CF}_{4}$ plasma etching was conducted slowly at a very low $\mathrm{rf}$ power as the last step of the reactive ion etching for contact window opening. The $\mathrm{CF}_{4}$ plasma etching conditions were : If power $=50$ watt, total pressure $=$ $150 \mathrm{mtorr}, \mathrm{CF}_{4}$ flow $=45 \mathrm{cc} / \mathrm{min}$, time $=20 \mathrm{sec}$. The junction leakages for the $\mathrm{W} / \mathrm{n}^{+}$contact with the $\mathrm{CF}_{4}$ plasma pretreatment was as low as those for the $\mathrm{Al} / \mathrm{n}^{+}$contact with no $\mathrm{W}$. The contact resistances for the silane reduced CVD W films $150 \mathrm{~nm}$ and $500 \mathrm{~nm}$ thick with $\mathrm{CF}_{4}$ plasma pretreatment are shown in Figs.6(a) and 6(b) respectively. The mean contact resistance of the $\mathrm{W} / \mathrm{n}^{+}$contacts with the $\mathrm{CF}_{4}$ plasma pretreatment for the $W$ film $150 \mathrm{~nm}$ thick (Fig. $6(\mathrm{a}))$ is $100 \mathrm{ohm}$ which is almost the same as that for the $\mathrm{Al} / \mathrm{n}^{+}$contacts with no W. In 


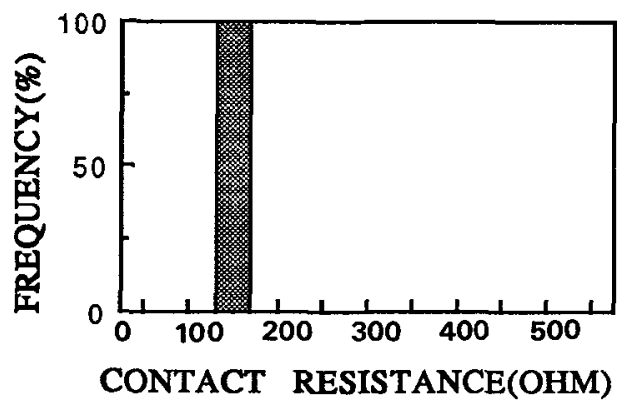

(a)

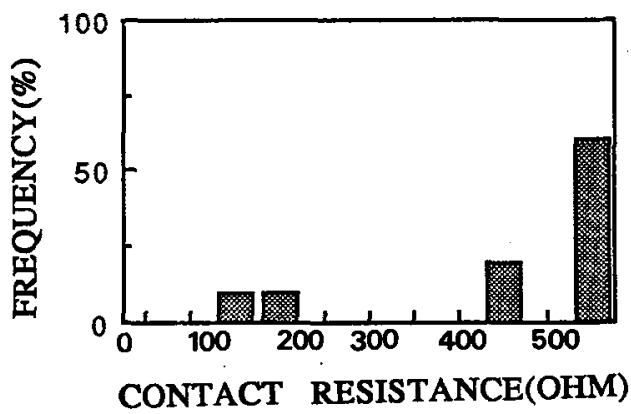

(b)

Fig. 6. Histograms showing the contact resistance distribution for the $\mathrm{SiH}_{4}$ reduced selective CVD W films (a) $150 \mathrm{~nm}$ and (b) $500 \mathrm{~nm}$ thick with $\mathrm{CF}_{4}$ plasma pretreatment

contrast the contact resistances of the $\mathrm{W} / \mathrm{m}^{+}$contacts with the $\mathrm{CF}_{4}$ plasma pretreatment for the W film $500 \mathrm{~nm}$ thick (Fig.6(b)) is widely distributed in the range from a few hundred to a few thousand ohm. This implies that the $W$ films in some of the 360 contact holes of the contact resistance test pattern were lifted when the $W$ film was thick $(500 \mathrm{~nm})$. Ohba et al[10] reported that the stress of the $W$ film deposited by IR heating from the wafer front is tensile for the $W$ film thickness $<200 \mathrm{~nm}$ and that the stress changes to compressive with increasing the $\mathrm{W}$ film thickness. The compressive stress of the $\mathrm{W}$ film $500 \mathrm{~nm}$ thick reaches about $8 \times 10^{9}$ dyne $/ \mathrm{cm}^{2}$ and the lifting of the $W$ film $500 \mathrm{~nm}$ thick may be due to this high compressive stress.

As we can see from the above discussion neither the $\mathrm{SF}_{6}$ nor the $\mathrm{CF}_{4}$ plasma pretreatment guarantees the selective CVD W films with good adhesion and low contact resistance as well as low junction leakages when the $W$ films are as thick as $500 \mathrm{~nm}$. Hence we decided to try two step and three step deposition processes to prevent $W$ lifting and to improve the electrical properties of the selective CVD $\mathrm{W}$.

First, we tried a two step $\mathrm{W}$ deposition process : hydrogen reduction process of $280 \mathrm{C}$ for $30 \mathrm{sec}$ for good adhesion followed by silane reduction process at $300^{\circ} \mathrm{C}$ for low leakages. The two step process was successful in preventing W lifting, but produced contacts with extremely high junction leakages (a few nA-a few $\mu$ A). The junction leakages may be caused by the lateral encroachment of $\mathrm{W}$ under the $\mathrm{Si}^{-\mathrm{SiO}_{2}}$ interface as shown in Figs. 7(a) and 7(b). The bright lateral lines along the Si-BPSG interface in Figs. 7(a) and 7(b) indicate the $W$ encroachment. We can see that the bright line for the deposition time of $60 \mathrm{sec}$ is thicker than that for $30 \mathrm{sec}$, which implies that the encroachment increases with increasing the deposition time.

Next, to improve the adhesion and junction leakage characteristics of the selective CVD W we tried a three step process : the first step of the silane reduction at $300^{\circ} \mathrm{C}$ for $40 \mathrm{sec}$, the second step of the in situ annnaling at $450^{\circ} \mathrm{C}$ for $120 \mathrm{sec}$ in $\mathrm{H}_{2}$, and the third step of silane reduction at $300^{\circ} \mathrm{C}$. Figs. $8(\mathrm{a})$ and $8(\mathrm{~b})$ show the contact resistance and junction leakage distributions for the $W$ film $500 \mathrm{~nm}$ thick deposited by the three step deposition process, 


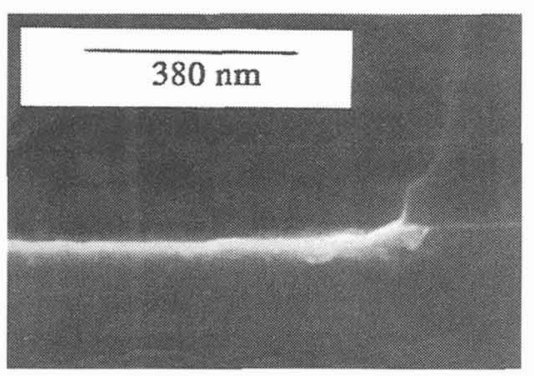

(a)



(b)

Fig. 7. Cross-sectional SEM micrographs showing lateral encroachment of $W$ under the $\mathrm{Si}-\mathrm{SiO}_{2}$ interface for the $\mathrm{H}_{2}$ reduced selective CVD W films deposited at 280 C (a) for $30 \mathrm{sec}$ and (b) for $60 \mathrm{sec}$

Fig. 8. Histograms showing (a) the contact resistance distribution and (b) the junction leakage distribution at $5 \mathrm{~V}$ reverse bias for the $\mathrm{SiH}_{4}$ reduced selective CVD W films $500 \mathrm{~nm}$ thick deposited by the two step process : $\mathrm{SiH}_{4}$ reduction $(300 \mathrm{C}, 40 \mathrm{sec}) /$ in situ annealing $(4500 \mathrm{C}, 120 \mathrm{sec}) / \mathrm{SiH}_{4}$ reduction $(300 \mathrm{c}, 100 \mathrm{sec})$

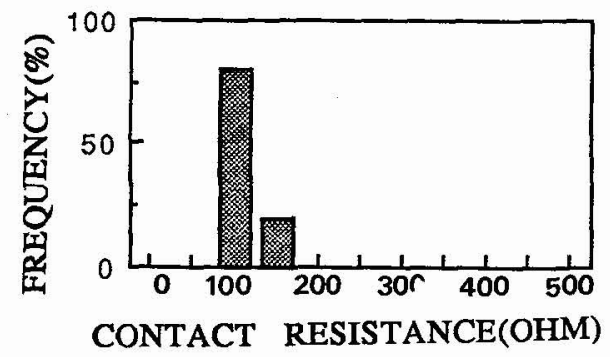

(a)

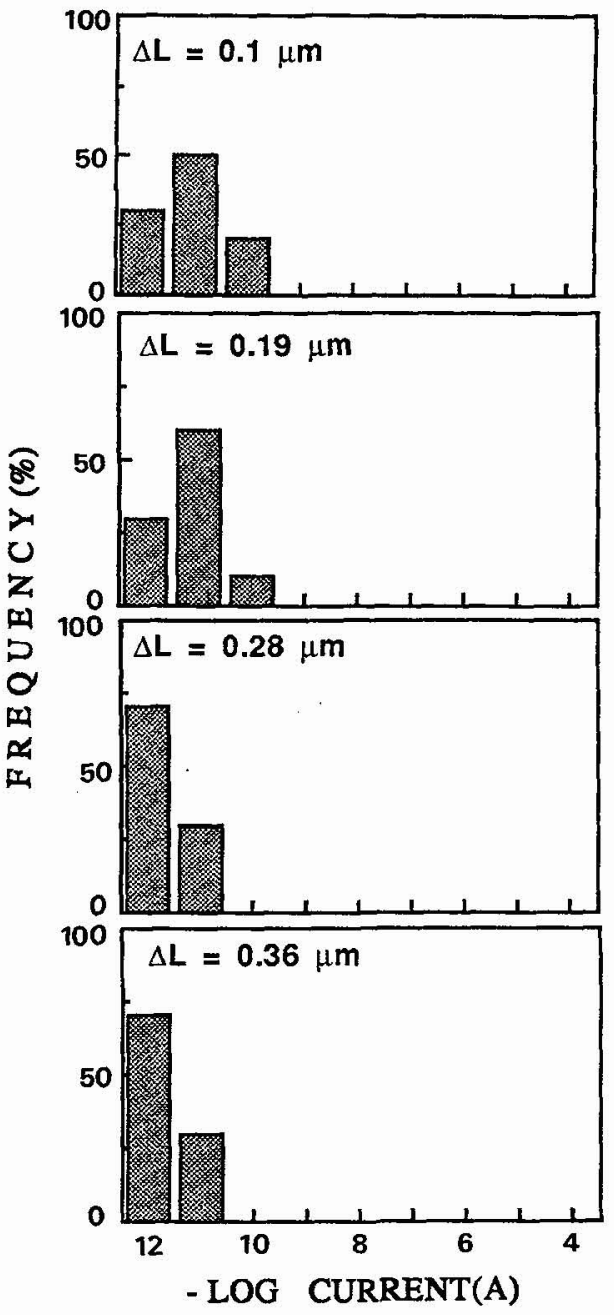

(b) 
the $\mathrm{Al} / \mathrm{n}^{+}$contact and no lifting was observed for the $\mathrm{W}$ film thickness of $500 \mathrm{~nm}$. The in situ annealing process seems to enhance the adhesion of $\mathrm{W}$ flims to the $\mathrm{Si}$ substrate by effectively lowering $W$ film stress and inducing interdiffusion of $W$ and $\mathrm{Si}$ at the W-Si interface.

\section{4) CONCLUSIONS}

The $\mathrm{SF}_{6}$ plasma pretreatment performed in situ prior to $\mathrm{W}$ depositon to remove the polymer films in contact holes has an enhancing effect on the adhesion of $\mathrm{W}$ films to the $\mathrm{Si}$ substrate but a degrading effect on junction leakages. The $\mathbf{C F}_{4}$ plasma pretreatment performed as the last step of the dry etching for contact window opening is more desirable than the $\mathrm{SF}_{6}$ plasma pretreatment in that the $\mathrm{CF}_{4}$ plasma pretreatment produces the W/Si contacts of good adhesion, low contact resistances and low junction leakages for thin $W$ films, although the $\mathrm{CF}_{4}$ plasma pretreatment produces the W/Si contacts of poor adhesion and high contact resistances for thick $W$ films. The adhesion and electrical properties of the silane reduced selective CVD W can be improved by the three step process of $\mathrm{SiH}_{4}$ reduction/in situ annealing $/ \mathrm{SiH}_{4}$ reduction.

\section{ACKNOWLEDGEMENTS}

The authors would like to thank Samsung Electronics and KOSEF (Korea Science and Engineering Foundation) for their support of this work through RETCAM(Research Center for Thin Film Fabrication and Crystal Growing of Advanced Materials).

\section{REFERENCE}

(1) T. Ohba, S. Inoue and M. Maeda, Proc. IEEE IEDM Tech. Dig., (1987) 213.

(2) H. Kotani, T. Tsutsumi, J. Komori and S. Nagao, ibid., (1987) 217.

(3) Y. Kusumoto, K. Takakuwa, H. Hashinokuchi, T. Ikuta and I. Nakayama, Proc. of Tungsten and other Refractory Metals For VLSI Applications III, Ed. by V. A. Wells, MRS, Pittsburgh, PA, (1988) 103.

(4) E. K. Broadbent and C. L. Ramiller, J. Electrochem. Soc., 131, (1984) 1427.

(5) W. T. Stacy, E. K. Broadbent and M. H. Norcott, J. Electrochem. Soc., 132, (1985) 444.

(6) E. K. Broadbent, A. E. Morgan, J. M. Deblasi, P. van der Putte, B. Coulman, B. J. Burrow and D. K. Sadana, J. Electrochem. Soc., 133, (1986) 1716.

(7) O. Yamazaki, S. Shimizu, H. Sakamoto, K. Mitsuhashi, K. Ohtake and M. Koba, VMIC Conf. Proc., (1989) 151.

(8) S. Wolf, "Silicon Processing for the VLSI Era" Vol. 2, Lattice Press, (1990) 129.

(9) H. Kotant and Nagao, IEDM, (1987) 217.

(10) M. Marinov, Thin Solid Films, 61, (1979) 363. 